\title{
El montaje de un musical como experiencia de Aprendizaje y Servicio en el Grado en Historia y Ciencias de la Música
}

\author{
Judith Helvia García Martín
}

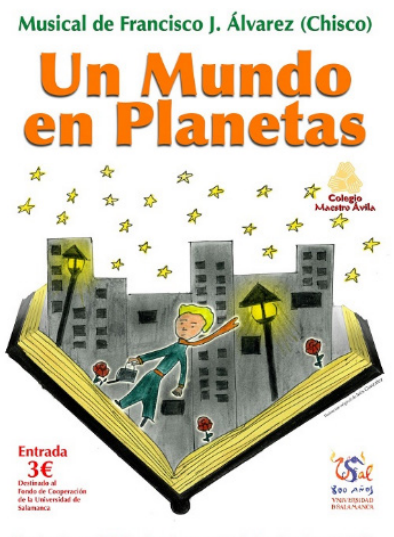

$\mathrm{D}$

EBIDO A AUSENCIA de prácticas curriculares en el Grado en Historia y Ciencias de la Música y con la intención de que los alumnos contemplen las diferentes salidas laborales de su titulación, se crea este proyecto en el que, aplicando el método Aprendizaje y Servicio (ApS), los alumnos de Grado trabajan en el montaje de una obra musical desde el inicio del proceso hasta la representación del mismo.

El objetivo principal es que los alumnos de Grado integren los conocimientos adquiridos en sus estudios en el contexto práctico de la Educación Primaria y Secundaria en un colegio con metodología inclusiva.

Los beneficiarios de esta actividad son los estudiantes de cuarto curso del Grado en Historia y Ciencias de la Música de la USAL, los alumnos del Colegio Maestro Ávila y la USAL y su programa del Fondo de Cooperación. 
La actividad nace en el curso 2016-2017 al observar que los estudiantes de este Grado apenas contemplaban una de las principales salidas de su titulación: el perfil profesional de docente musical en Educación Secundaria.

Concretamente, los estudiantes de la titulación que participan son aquellos que han cursado las materias «Musicología aplicada a la docencia», «Didáctica de la Expresión Musical» $\mathrm{y}$ «Musicoterapia».

Esta iniciativa se desarrolla durante los meses de septiembre a junio en el Colegio Maestro Ávila de Salamanca en formato de actividad extraescolar.

Entre la profesora coordinadora y la profesora de música del Colegio deciden el compositor con el que se colaborará. Una vez elegido, se pone en conocimiento de los estudiantes de cuarto curso de Grado esta actividad, que puede constituir sus prácticas extracurriculares.

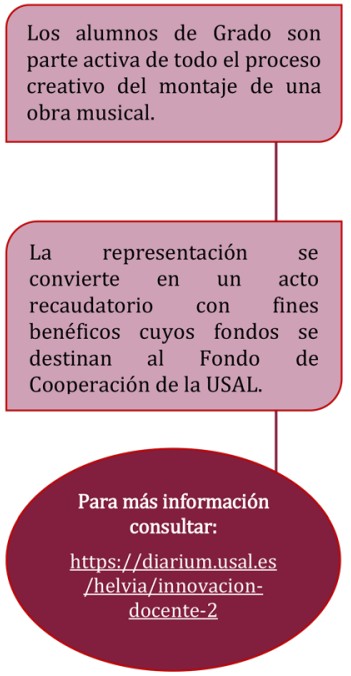

Los ensayos comienzan en el mes de octubre tras haberse reunido con el autor de la obra. Habrá un total de dos ensayos por semana en horario de tarde, y algunas de las tareas que llevarán a cabo los alumnos de Grado en estos ensayos serán:

- Dirigir el coro.

- Acompañar los ensayos con piano y otros instrumentos.

- Arreglar las partituras y el libreto.

- Crear coreografías.

Con el fin de acostumbrar al coro y sus directores a la dinámica de las actuaciones, se llevan a cabo representaciones parciales a lo largo del curso escolar, que coinciden con las fiestas de Navidad, Carnaval y la fiesta del colegio.

La función final tiene lugar en el Teatro Juan del Encina en la primera semana de junio. La entrada tiene un coste simbólico de $3 €$ y la recaudación se destina, desde pasadas ediciones al Fondo de Cooperación de la USAL.

En el último curso y gracias al Servicio de Voluntariado del SAS de la USAL, se ha podido realizar la representación del musical en otras localidades. Además, se ha colaborado con el Servicio de Innovación y Producción Digital de la USAL.

La recaudación ha ido ascendiendo curso tras curso, llegando casi a $700 €$ en la última edición.

Al finalizar, se realiza una encuesta de satisfacción tanto a los alumnos de Grado como a los del Colegio, obteniendo unos altos niveles de satisfacción con la actividad desarrollada. De hecho, los alumnos de Grado destacan que se trata de una actividad con gran potencial como herramienta formativa creativa que les acerca a las salidas laborales de la titulación.

Para la divulgación de la actividad se han utilizado redes sociales y canales como YouTube, las memorias de los proyectos de innovación a los que se adscribe esta iniciativa y píldoras de información sobre el proyecto. 